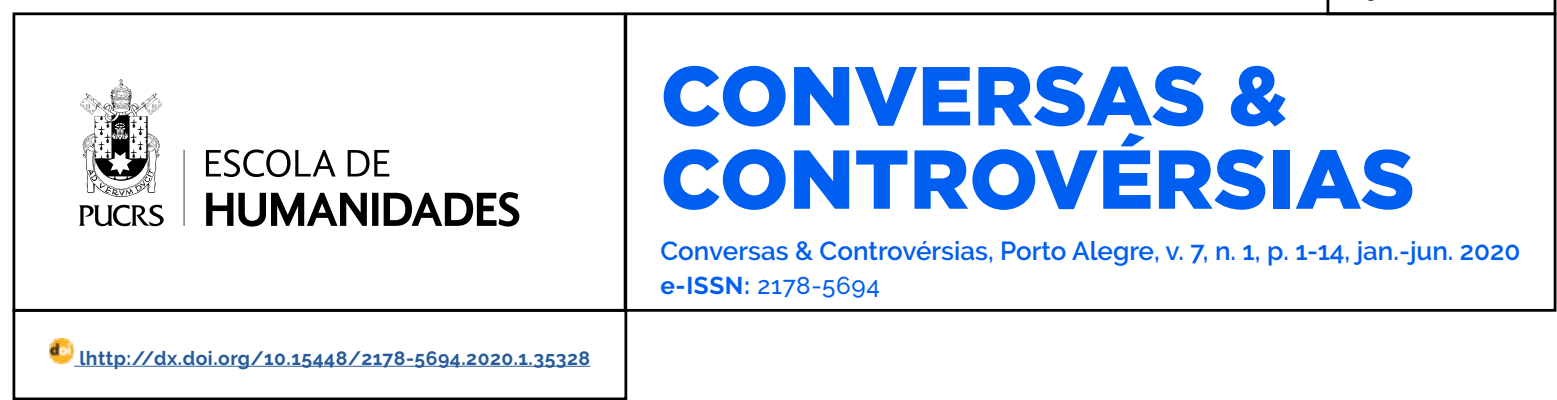

SEÇÃO: DOSSIÊ JUVENTUDES, PARTICIPAÇÃO E POLÍTICAS PÚBLICAS

\title{
Likes, memes e militância: ciberativismo na Internet brasileira
}

\author{
Likes, memes and militancy: cyberactivism on the Brazilian internet
}

\author{
Ana Nolasco ${ }^{1}$ \\ orcid.org/0000-0001-7450-0815 \\ hadaig@gmail.com
}

\section{Leonardo Frosi Ávila ${ }^{1}$}

orcid.org/0000-0003-1444-7367

frosingrado@gmail.com

\section{Airton Luiz Jungblut ${ }^{1}$}

orcid.org/0000-0002-0987-4244

jungblut@pucrs.br

Recebido em: 15 ago. 2019.

Aprovado em: 9 mar. 2020 Publicado em: 17 set. 2020

\section{(c) (1)}

Artigo está licenciado sob forma de uma licença Creative Commons Atribuição 4.0 Internacional.
Resumo: O presente artigo tem por objetivo investigar a influência do processo de revolução comunicacional provocado pela Internet na esfera política, focando no conceito de "ciberativismo". Busca-se evidenciar as caracteristicas particulares do ativismo praticado no ciberespaço. Para isso, são de interesse as motivações individuais para a ação política no ciberespaço, nos utilizando da noção de agência enquanto capacidade de ação mediada por uma situação social, que pode ser classificada de acordo com um continuum de intencionalidade representando os graus diferentes de consciência que existem em diferentes tipos de agência. Outro eixo de análise é a hipótese de que os "materiais não humanos" são actantes, exercendo agência sobre os atores humanos no ciberespaço. Essas análises serão produzidas por meio de observação e tipificação de diferentes práticas que podem ser consideradas ciberativistas, tendo como foco, principalmente, grupos da rede social Facebook, a rede social de microblogging, Twitter, o aplicativo de mensagens WhatsApp, entre outros.

Palavras-chave: Ciberativismo. Ciberacontecimento. Internet. Agência. Método etnográfico.

Abstract: This paper aims to investigate the influence of the communicational revolution provoked by the Internet on the political sphere, focusing on the concept of "cyberactivism". It seeks to highlight the particular characteristics of activism practiced in cyberspace. To this end, individual motivations for political action in the cyberspace are of interest, using the notion of agency as a capacity for action mediated by social situations, which can be classified according to a continuum of intentionality representing the different degrees of consciousness existent in different types of agency. Another axis of analysis is the hypothesis that the "non-human materials" are active, exerting agency over human actors in the cyberspace. This analysis will be produced through observation and typification of different practices that can be considered cyberactivist, focusing mainly on Facebook groups, Twitter, WhatsApp, among others.

Keywords: Cyberactivism. Cyber-event. Internet. Agency. Ethnographic method.

\section{Introdução}

Este artigo trabalha com o conceito de "ciberativismo", termo que tem sido utilizado para nomear a ação politica praticada no ciberespaço. Existem diversas conceituações de ciberativismo. David de Ugarte (2008, 111 citado por Araújo 2011, 5) o define como uma estratégia elaborada por grupos que utilizam a Internet para mudar a agenda pública, pautando o cotidiano com temas de interesse de determinado movimento, alçando tais ideias aos meios de comunicação tradicionais. Ele determina dois tipos de atuação ciberativista: aquela informada pela lógica de campanha, com ações organizadas por um centro para difusão de uma ideia, e a mobilização em busca da criação de um grande debate social 
distribuido. O autor considera a Internet uma rede distribuida, e considera que as ações ciberativistas surgem quando "alguém propõe e soma-se a ele quem quer. A dimensão da ação dependerá das simpatias e do grau de acordo que suscite a proposta" (Ugarte 2008, 35 citado por Araújo 2011, 5). Mais autores ressaltam outras características da Internet, como Alexander Galloway, que observa que a Internet, enquanto rede de redes conectadas, tem uma estrutura vertical (DNS) e uma horizontal (TCP/IP) (Galloway 2004, 53 citado por Araújo 2011, 6). Essas duas estruturas estariam em contradição: o tráfego de informação na Web estaria submetido à estrutura vertical para ter acesso à estrutura anárquica e radicalmente horizontal da Internet. A estrutura hierárquica, vertical do DNS (Domain Name System, o sistema de localização de nomes de domínios) definiria um conjunto de regras e recomendações que seguem padrões técnicos específicos, definindo os padrões de comportamento possiveis, e é sob o controle dessa estrutura hierárquica que a estrutura horizontal da Internet precisa operar, o que cria limites à ação livre na Internet.

O sociólogo Sérgio Amadeu da Silveira (2009) reconhece essa contradição, mas vê um grande campo para atuação nas brechas proporcionadas por essa ambiguidade, ressaltando que: a) o conjunto TCP/IP, apesar de tornar necessário para se comunicar na Internet ter um IP, não exige vinculação de uma identidade civil a esse número de IP para que a comunicação se estabeleça, assegurando assim a comunicação anônima (Silveira 2009, 120); b) que "tecnologias do anonimato" - como a aplicação Tor, software que impede a análise de tráfego, distribuindo a comunicação através de uma rede de voluntários transmissores ao redor do mundo (Tor 2009 citado por Silveira 2009) e impedindo o monitoramento da conexão e dos sites acessados - assegura ainda mais a possibilidade de comunicação anônima, não permitindo que se descubra a localização física dos interagentes (Silveira 2009, 121); c) e que o caráter de "esfera pública interconectada" da Internet, em oposição à esfera pública controlada pelos mass media, proporciona baixos custos para se tornar um falante e ter acesso à arquitetura informacional distribuida, sem necessidade de autorizações e controles para dela participar (Benkler 2006 citado por Silveira 2009, 126).

André Lemos (2004 citado por Araújo 2011, 7), define três grandes tipos de ciberativismo:

1. conscientização e informação, como as campanhas promovidas pela Anistia Internacional, Greenpeace ou a Rede Telemática de Direitos Humanos; 2. organização e mobilização, a partir da Internet, para uma determinada ação (convite para ações concretas nas cidades) e: 3.iniciativas mais conhecidas por "hacktivismo", ações na rede, envolvendo diversos tipos de atos eletrônicos como o envio em massa de emails, criação de listas de apoio e abaixo-assinados, até desfiguramentos (defacing) e bloqueios do tipo DoS (Denial of Service). (Lemos 2004, 1, citado por Araújo 2011, 7)

Uma vez que o campo de atuação do ciberativismo está em constante processo de mudança, há autores como Rodrigues e Pimenta (2015), que buscam uma definição mais ampla de ciberativismo:

\begin{abstract}
O termo "cyber" surge, pela primeira vez, nos trabalhos de um dos fundadores da Cibernética, o pesquisador Norbert Wiener, em 1939. A partir daí passa a designar sistemas mecânicos simulando comportamentos complexos dos seres vivos. Também há outra definição, tratando-se de universos virtuais, gerenciado por máquinas. Já a palavra "ativismo", segundo o dicionário Michaelis, possui dois significados: "1. Acentuação da atuação consequente da vontade, na formação da cultura e da sociedade; toda criação espiritual, bem como a arte e a teoria científica devem servir à atividade dirigida a uma meta. 2. Doutrina ou prática de dar ênfase à ação vigorosa, por exemplo, ao uso da força para fins políticos". Assim, temos uma definição interessante, ainda que precise ser aprimorada e refinada: a utilização de sistemas mecânicos que simulem comportamento dos seres vivos ou de universos virtuais para, deliberadamente, agir com o propósito de interferir na formação da cultura e da sociedade, visando atingir uma meta. (Rodrigues e Pimenta 2015, 5)
\end{abstract}

Essa definição possibilitaria dar conta de novos atores da Internet como o Wikileaks (com suas ações de hacking, uso da criptografia e o vazamento de informações utilizando essa tecnologia). Também o grupo Anonymous (que também faz ações hackers), cujas ações nem sempre trans- 
bordam para o mundo off-line, o que os excluiria, por exemplo, da definição de Ugarte, que definiu ciberativismo fazendo referência ao objetivo de que as ações na Internet tenham peso fora dela, considerando a rede apenas como um fator de aumento de capacidade comunicacional, sem a devida ênfase às suas próprias capacidades como meio (Rodrigues e Pimenta 2015, 5).

Muito da produção acadêmica que trata desse tema tem permitido compreender as lógicas organizacionais acionadas nessas ações em rede. Contudo, buscamos, neste artigo, compreender as autonomias e as motivações individuais dos agentes nelas envolvidos (Jungblut 2015). Há uma diversidade de grupos políticos, partidos, ONGs que utilizam a Internet empregando a mesma lógica da ação política profissional que utilizam fora dela. Pouco se sabe, no entanto, sobre aqueles atores cuja ação política é influenciada pelas caracteristicas próprias do ciberespaço, como procedem e quais são suas motivações individuais. Nesse campo, podemos encontrar um ambiente rico para a pesquisa, que pode nos informar a respeito de um novo tipo de ativismo, com formas rigorosamente particulares, diferentes das que observamos no mundo off-line.

Os atores que utilizam o ciberespaço têm à sua disposição funções como o já mencionado anonimato, que os libertam de muitos constrangimentos sociais, e funções específicas de determinados sites como o botão like (curtir) do Facebook, ou as hashtags do Twitter. São ferramentas existentes na Internet que permitem adesões e/ou manifestações rápidas sobre uma causa, permitindo um engajamento político sem compromissos, preocupações e monitoramento posterior, com manifestações de afinidades, simpatias, concordâncias, ou o oposto disso, desconformidade, antipatia, discordância, repúdio etc. O espaço da Internet, e particularmente dos fóruns disponiveis (como no próprio Facebook, mas existem muitos outros), também costuma permitir, facilitar, ou, até mesmo, influenciar, discussões intermináveis sobre determinado tema, com inúmeros confrontos argumentativos, inúmeras versões de uma mesma argumentação, que podem seguir por diversos posts, tópicos, tweets etc. Esses espaços são propícios para a reflexividade política, para o desenvolvimento de determinada opinião, para a escolha de determinado "lado", potencializando a autonomia do usuário e o motivando a propagar discussões e posições de um modo que podemos entender como uma forma de ativismo. São diversas formas de ação política, que formam um continuum entre aquelas de baixa intencionalidade conscientizada, e aquelas de alta intencionalidade conscientizada. Podemos entender as que possuem pouco ou baixissimo grau de intencionalidade conscientizada como um like ou a adesão a um hashtag vinculados a ações políticas, ainda mais se considerarmos que o ciberespaço permite que elas circulem de maneira rápida e massiva, influenciando outros atores em um número considerável. Um pequeno texto político, divulgado por um usuário do aplicativo de mensagens Whatsapp para todos os membros da sua lista de contatos, ação que pode ser feita em segundos e que não necessariamente é fruto de ponderações mais elaboradas quanto a sua intenção, nem monitorada quanto aos seus efeitos, pode ter uma circulação tão massiva a ponto de ter peso em importantes discussões políticas do mundo off-line.

É possivel investigar e analisar essas ações, definindo de forma concreta o que podemos considerar "ação política" no ciberespaço? É possivel tipificar conceitualmente as situações observáveis neste espectro de possibilidades? Para esta análise, utilizamos o conceito de agência de Laura Ahearn, que a define como uma capacidade de ação que é "socioculturalmente mediada", e de Sherry Ortner, que demonstrou que existe um continuum entre diferentes definições de agência: o polo das definições soft, que abrange definições de agência em que as intenções não necessitam estar bem conscientizadas nas ações dos atores, e o polo hard, definições onde está prevista a existência de um desejo mais conscientizado, de intenções mais formalizadas, com planejamento e monitoramento dos desdobramentos posteriores. Entre o projeto objetivamente conscientizado e o quase inconsciente desejo de algo há um continuum onde existe uma série de posições 
intermediárias de "agência", bem como a possibilidade de evolução da situação soft para uma mais hard (Jungblut 2015). Se usarmos a noção de agência, entendida como capacidade de agir socialmente sobre determinada situação, com graus diferentes de intencionalidade conscientizada, poderemos analisar a variedade de ações políticas que ocorrem no ciberespaço, situando no polo hard aqueles agenciamentos políticos que trabalham com alto planejamento e monitoramento, como os dos grupos, partidos políticos, Ongs etc., além dos usuários da Internet mais empenhados em utilizá-la como lugar de discussão e divulgação política, e no polo soft aqueles agenciamentos políticos fragilmente conscientizados, aquelas manifestações curtas permitidas pelo ciberespaço de apoio a causas, posições políticas, movimentos etc., às vezes até mesmo por impulsos momentâneos.

Também utilizamos o conceito de "ciberacontecimento", termo que, segundo Jungblut (2011 citado por Arias 2008), dá conta daqueles episódios em que há "'propagação explosiva de informação' no ciberespaço causada pela divulgação de fatos com grande capacidade de mobilização de atenção através, quase sempre, de material visual, sonoro ou audiovisual", e a Teoria do Ator Rede (TAR), de Bruno Latour, que nos informa que os "materiais não humanos" (máquinas, plataformas, sites etc) podem ser entendidos como sujeitos de agência, servindo de "pano de fundo da ação humana, [... podendol autorizar, permitir, dar os recursos, alentar, sugerir, influir, bloquear, fazer possivel, proibir, etc." (Latour 2008, 107).

$\mathrm{Na}$ Internet ocorre, muitas vezes, a explosão de postagens e de discussões impulsionadas por determinado video da plataforma de compartilhamento de videos no YouTube, alguma postagem de denúncia de algum fato off-line, ou postagens de denúncia de outras postagens e de outros usuários do ciberespaço, fotos polêmicas, postagens em blogs etc., que podemos classificar dentro do conceito de "ciberacontecimento".
Nessa perspectiva cabe analisar como um acontecimento é influenciado pelo funcionamento dos materiais não humanos, que de certa forma afetam a forma de mobilização dos usuários, monitorá-lo, buscar informações atualizadas, agir sobre ele, de modo a observar como o acontecimento vai se desdobrando em vários fatos nos quais os usuários e os materiais não humanos se influenciam mutuamente. Uma análise sobre esses materiais não humanos, pressupondo sua actância, nos permite "inventar", segundo Latour, "truques para podermos fazê-los falar, quer dizer, fazê-los oferecer descrições de si mesmos, produzir roteiros do que fazem para outros humanos e não humanos" (Latour 2008, 117). Podemos com esse instrumento buscar entender a relação entre os materiais não humanos e o funcionamento das intencionalidades dos atores do ciberespaço.

\section{Vizinhos do Centro Histórico}

Buscamos, para os propósitos dessa análise, escolher diversos espaços propícios para a observação da prática ciberativista em ação, como a rede social Facebook e, mais especificamente, 0 recurso que permite a criação de "grupos" que se propõem a ser espaços de debates sobre qualquer tema; e a rede social de microblogging, Twitter. No Facebook, observamos durante todo o ano de 2017 as atividades do grupo "Vizinhos do Centro Histórico - Poa"2, que costuma ter muitas discussões de cunho político, com mais de 30 mil membros, de todas as posições políticas, moradores, ou não, do bairro Centro Histórico. Selecionamos aqui o que observamos e analisamos das discussões no grupo referentes à reintegração de posse da ocupação Lanceiros Negros, em Porto Alegre, no dia 14 de junho de 2017, por avaliarmos que foi a atividade que mais nos permitiu verificar o funcionamento de um ciberacontecimento e a interação entre o mundo on-line e off-line decorrente desse. A ocupação Lanceiros Negros foi a ocupação organizada pelo Movimento de Luta nos Bairros, Vilas e Favelas (MLB) de um imóvel abandonado pelo poder público há 12 anos. Era moradia para

2 Vizinhos do Centro Histórico é um grupo público do Facebook. https://www.facebook.com/groups/centrohistoricodeportoalegre/ 
pessoas que saiam de zonas de tráfico, regiões perigosas ou que tinham que morar na rua por não conseguir pagar o aluguel. Contava com 50 quartos construidos pelos próprios moradores, biblioteca com cerca de 500 livros, cozinha com três geladeiras, dois fogões, micro-ondas e demais utensilios, oficinas de teatro, yoga, aulas de judô e boxe (Uhr 2016). Foi realizado um acompanhamento dos desdobramentos das discussões virtuais por parte de ativistas da causa da moradia, pessoas ligadas à movimentos sociais, e pessoas não vinculadas a nenhum grupo que apenas se expressam na internet através do grupo do dia 14 de junho de 2017, até o dia 20 de junho de 2017 (periodo em que essa discussão estava em alta no grupo). Foram analisados cerca de quatro tópicos criados no grupo, com mais de 750 comentários, com pessoas expressando suas opiniões tanto à favor da reintegração de posse como contra, além de opiniões mais gerais sobre ocupações, movimentos pela moradia, esquerda e direita política e o cenário político de 2017, tanto de Porto Alegre como do estado do Rio Grande do Sul e do Brasil. ${ }^{3}$

É notável que o grupo serve como uma comunidade de compartilhamento de informações instantâneas sobre a reintegração de posse, por meio de discussões sobre os termos da reintegração, e pelas informações de pessoas que estão presentes na reintegração e ao mesmo tempo postando informações no grupo. Desse modo, é driblado o poder de monopólio das grandes empresas de comunicação, que podem não ter interesse em noticiar, ou em noticiar de forma rápida a reintegração de posse que estava ocorrendo naquela madrugada. É superado tanto o poder de monopólio da informação por parte da mídia quanto a lentidão da informação, pois se os jornais televisivos tradicionais informariam desta reintegração só no dia seguinte, ou até depois disso, nesse grupo de Facebook as informações ocorrem em tempo real, até mesmo com vídeos. Um dos comentários diz: "Gente, quem tiver por perto com fotos e etc, acionem alguma emissora de televisão. Eles fazem isso de noite achando que podem esconder da gente essa barbaridade de despejar as pessoas na rua!!!". Em resposta a esse comentário, surge este: "Eles barraram o acesso da mídia". Como resposta: "Até aéreo? Quem puder, por favor faça o papel da mídia independente!!! Gravem, tirem fotos e espalhem para emissoras também". Temos aqui, portanto, o compartilhamento de uma informação valiosa: a polícia, na hora da reintegração de posse, estava barrando o acesso da mídia tradicional. Tal informação, sem a Internet, talvez nunca teria sido tão facilmente disponibilizada para o conhecimento de um grupo com mais de 30 mil pessoas; estaria, pelo contrário, restrita a grupos militantes que participaram presencialmente da resistência contra a reintegração de posse e pessoas próximas, pelo boca a boca. Há, ainda, o incentivo para que alguém vá até o local e filme de forma independente, fazendo o papel de "midia independente", para divulgar depois os vídeos no grupo e, talvez, até mesmo nas emissoras. E é o que muitas pessoas fazem: é possivel ver no grupo tanto os videos retratando a violência policial quanto muitas fotos da reintegração, de diversos ângulos com comentários como os que seguem:

\footnotetext{
- Tá horrivel aqui!

- Tem gente indo pra lá dar apoio e ajudar na resistência. Quem puder, vá!

- Olha gente... da janela vejo horrores... vão arrancar a porta com corrente e caminhoneta do choque

- Meu deus quantos gritos!

- Nojo... arrancaram a porta... grito de guerra do choque!

São fornecidas informações sobre as familias despejadas:

- Pessoal, tem famílias da Lanceiros Negros que foram acolhidas na Mirabal ali na Duque. Estão pedindo para doarem alimentos e cobertas. Por favor ajudem!

Discussões sobre os termos da reintegração:

Mas eles não estão lá com proteção judicial?" [comentário respondido com:] «Ñ. O juiz autorizou.

A BM tá cumprindo ordem judicial então? Não foi canetaço do Sartori? [Governador],
} 
$\tilde{N}$, foi uma longa batalha judicial, de um lado a Defensoria Pública, do outro o Gringo ISartori, Governador].

Simultaneamente a todos esses aspectos possibilitados pelo grupo, pessoas se manifestam a favor ou contra a reintegração de posse:

Uma vergonha!! Reintegrar um prédio que estava abandonado lemoticon de rosto enfurecido], Gringo nojento!!

Pode ser triste e tudo mais, mas continuo sendo contra a invasão, como não gostaria que invadissem minha casa...

Também ocorrem discussões paralelas ocorrendo especificamente em pequenos fóruns que podem ser abertos embaixo de cada comentário. Outrossim, é possivel «curtir» os comentários, o que permite o engajamento com pouco esforço no ato de concordar com uma posição ou outra.

Há, também, a criação de "memes", ou uso de "memes" já existentes, que são imagens de cunho humoristico e/ou de denúncia de determinada atitude, político, personalidades em geral etc. Não são necessariamente de cunho político, mas, nessas discussões, os que surgem geralmente são assim. A ideia de meme é carregada de polissemia (Pereira 2018, 19), não tem nítidos contornos e pode abranger desde imagens e gifs utilizados como forma de reação a comentários no Facebook ou Twitter a bordões reproduzidos on-line. É "altamente passivel de transformações e ressignificações, em um processo onde o direito de propriedade intelectual é praticamente ignorado" (Pereira 2018, 19). Memes têm a ver com "propagação, imitação e cópia", o seu sucesso estaria na facilidade de "recriar conteúdos virais por meio de paródias, readaptações e derivações com diferentes conteúdos, mas mantendo algo da matéria prima" (Pereira 2018, 19). Um meme, que parece ter sido feito no calor da discussão, usa fotos de Sartori ao lado de uma foto de Hitler, com os dizeres "Nazigringo!". É fácil confeccionar uma imagem assim e ela serve como uma exposição de uma ideia política facilmente reconhecivel e compreensivel (Sartori, por ter assinado a reintegração de posse, seria autoritário, antipopular etc., da mesma forma que Hitler), que pode ser facilmente salva no computador de qualquer pessoa e compartilhada por essa em vários outros lugares, ou no seu perfil pessoal. Também é muito fácil modificar a imagem, acrescentando elementos, seja para concordar, discordar, ironizar. "Uma das principais características destas novas mídias é a intertextualidade. Os memes se relacionam entre si e se referenciam porque os seus criadores os conectam" (Shifman 2014, citado por Pereira 2018, 20). Pesquisadoras como Shifman (2014 citado por Pereira 2018) veem o fenômeno como positivo:

\begin{abstract}
Os usuários da Internet estão descobrindo algo novo, e os pesquisadores devem segui-los. Os usuários parecem ter percebido que o conceito de meme encerra alguns dos aspectos mais fundamentais da cultura digital contemporânea. Como muitos aplicativos da Web 2.0, os memes se difundem de pessoa para pessoa, mas moldam e refletem as mentalidades sociais gerais. O termo descreve a reprodução cultural como impulsionada por vários meios de cópia e imitação - práticas que se tornaram essenciais na cultura digital contemporânea. (Shifman 2014. 4 citado por Pereira 2018, 20, tradução nossa)
\end{abstract}

Autores como Jenkins (2008 citado por Cardoso 2016) veem nesse fenômeno um processo de cultura participativa, modificando a noção antiga de que o espectador é passivo em relação ao que assiste, lê ou ouve (Cardoso 2016, 18). "O consumo tornou-se um processo coletivo" (Jenkins 2008, 38 citado por Cardoso 2016, 18), e "a cultura popular assumiu novas responsabilidades ao instruir o público sobre o que estava em jogo nessa eleição e inspirá-lo a participar mais plenamente do processo" (Jenkins 2008, 50 citado por Cardoso 2016, 18), se referindo às eleições norte-americanas de 2004. Colocar um ponto de vista em uma imagem visando a sua circulação na Internet seria um ato de cidadania tão importante quanto escrever uma carta para ser publicada na sessão de leitores de um jornal e enviar um meme sobre um político tão importante, para um número crescente de jovens, quanto entregar um panfleto na rua (Jenkins 2008 citado por Cardoso 2016).

Outros autores poderiam dizer que fenômenos como esse, permitidos pela Internet, seriam característicos do chamado "slackativismo", ou "ativismo de sofá" (Klang e Madison 2016). Nessa linha de interpretação, fazer memes, "curtir", "compartilhar", assinar uma petição etc. faria parte de uma forma de ativismo que não resulta em 
mudanças estruturais reais, dando uma sensação de satisfação às pessoas que o praticam, fazendo-as se sentirem bem e julgarem que já estão ajudando causas sociais importantes o suficiente e, assim, não sentirem necessidade de participar do ativismo e da militância política tradicionais. De qualquer forma, como analisaremos mais a fundo posteriormente, muito do que acontece no ciberespaço tem peso na discussão política fora dele, de modo que sua influência não pode ser desconsiderada. Mesmo no exemplo do grupo "Vizinhos do Centro Histórico", por mais que a possibilidade de "curtir", comentar, fazer memes possa funcionar como algo que deixa os usuários do grupo satisfeitos, a ponto de não sentirem necessidade de ir presencialmente na manifestação contra a reintegração de posse, muitas das interações eram baseadas no incentivo a comparecer. Além disso, é relevante estudar as formas particulares do ciberativismo, por exemplo, para perceber como funciona a já mencionada democratização da informação, que não vem mais apenas "de cima", de fontes como a mídia tradicional e, sim, de forma mais horizontal por vários grupos diferentes produzindo discursos políticos, muitas vezes conflitantes.

O grupo "Vizinhos do Centro Histórico" permite inúmeras formas de ação e de discussão política acontecendo simultaneamente, uma explosão de diferentes aspectos de engajamento político: discussão sobre concordar ou não com a reintegração, discussão e informação sobre os termos técnicos, quem permitiu etc.; mobilização e incentivo para comparecer ao ato presencial ou agir como midia independente etc. O que se observa é uma disputa de narrativas a partir da publicação de um acontecimento político. O acontecimento, ao ser publicizado ou conhecido no ciberespaço, não tem um significado fixo, pronto: o significado vai ser construído por uma disputa entre interpretantes, e isso sempre sujeito a mudanças de acordo com o surgimento de novos elementos. Nem sempre haverá um consenso, de modo que as disputas de construção de significado podem se dividir entre dois ou mais grupos. Esse fenômeno tem muita relevância se operarmos sob a perspectiva acima mencionada de que a prática ciberativista baseada, por exemplo, na confecção de coisas como memes, está inserida em um processo de democratização da informação e da construção dos significados dos discursos politicos que circulam na sociedade. A Internet permite uma maior maleabilidade para a construção das informações e dos discursos políticos, um ritmo mais acelerado de discussão e de ressignificação do que é recebido por fontes como a mídia tradicional, produzindo uma acalorada disputa entre grupos que disputam para ver qual têm a narrativa "verdadeira", quem constrói a "verdadeira informação" sobre determinado acontecimento. Aqui, podemos pensar nos efeitos do "viés de confirmação" (Braga 2018, 211) na formação de diferentes grupos de pessoas que concordam entre si e como essa concordância é construída.

Quando um grupo de pessoas se une no ciberespaço em prol de uma causa política específica, podemos compreender de que forma isso acontece com o conceito de "ação conectiva" e suas diferenças em relação à "ação coletiva", de Bennett e Segerberg (2012):

A lógica de ação coletiva que tipifica a ordem social moderna de instituições hierárquicas e grupos de associação salienta o dilema organizacional de conseguir fazer com que individuos superem a resistência a se juntar à ações onde os custos da participação pessoal podem ultrapassar os ganhos marginais, particularmente quando pessoas podem "pegar carona" nos esforços de outros de graça, e colher os benefícios se os outros conseguirem ganhos. Em resumo, a ação coletiva convencional tipicamente requer que pessoas façam escolhas mais dificeis e adotem mais identidades sociais auto-mutáveis do que a DNA (digitally networked action, ação em rede digital) baseada em quadros de ação pessoal organizados em torno de tecnologias sociais. A propagação de identificações coletivas tipicamente exige mais educação, pressão, ou socialização, o que por sua vez traz maiores demandas quanto a organização formal e recursos como dinheiro para pagar aluguel para escritórios de organização, para gerar publicidade, e para 
contratar equipes de organizadores profissionais (McAdam et al. 1996 citado por Bennett e Segerberg 2012). A mídia digital pode ajudar a reduzir os custos nestes processos, mas elas não mudam fundamentalmente as dinâmicas de ação. (...) O modelo alternativo emergente que chamamos de lógica da ação conectiva se aplica cada vez mais à vida nas sociedades modernas tardias nas quais organizações formais estão perdendo seu controle dos indivíduos, e laços de grupo estão sendo substituídos por redes sociais fluidas, de larga escala (Castells 2000 citado por Bennett e Segerberg 2012). Essas redes podem operar principalmente pelos processos organizacionais da rede social, e sua lógica não exige um forte controle organizacional ou a construção simbólica de um unido "nós". A lógica da ação conectiva, sugerimos, implica uma dinâmica própria e, portanto, merece uma análise em seus próprios termos analíticos (Bennett e Segerberg 2012, 748, tradução nossa).

Segundo essa análise, a formação de concordâncias e de grupos em torno de causas políticas no ciberespaço se dá em termos particulares, diferentes da "ação coletiva" do ativismo e da militância política tradicionais. É uma ação que precisa se apoiar menos na construção simbólica de um unido "nós" para impulsionar a participação, criando ao invés disso uma ação em conjunto que impulsiona a participação dando espaço para a expressão individual. É neste contexto que as rápidas discussões de Internet, os comentários e os memes se dariam: a possibilidade de expressão individual, mesmo que em união com outras pessoas por uma mesma causa, impulsiona a participação, pois não haveria tanta lentidão e dificuldade para os individuos compreenderem como o movimento é benéfico para sua vida. A participação por meio da sua expressão individual já seria uma satisfação imediata. Se forma um contexto em que se torna possivel tanto a variedade de manifestações individuais quanto a rapidez na construção de narrativas que vão disputando entre si.

No Twitter, rede social de microblogging, pudemos constatar que os tweets, postagens curtas de no máximo 280 caracteres (até o final de
2017, o limite era 140 caracteres), são um espaço propício para a construção rápida de significação para determinado acontecimento. Dois casos são um exemplo dessa disputa de narrativas: o atentado contra o então candidato à presidência da república Jair Bolsonaro, e o assassinato da vereadora Marielle Franco. Tweets dos dois lados da disputa acusam o outro de querer visibilizar a violência política cometida contra o seu lado político ao mesmo tempo em que ignoram a violência contra o adversário político, ou seja, uma acusação mútua de falta de coerência. Não há uma checagem de fatos ou um grande compromisso ao escrever um tweet, de modo que, se um usuário do Twitter escreve que o outro lado, por exemplo, "riu do atentado a Jair Bolsonaro enquanto reclama da morte de Marielle Franco", é provável que os seguidores (parecido com o recurso "Amigos" do Facebook, os seguidores veem os tweets de quem eles seguem na página inicial) do perfil desse usuário, que se são seguidores o são por, provavelmente, já terem uma concordância prévia com as ideias políticas que compartilham diariamente, vão acreditar na narrativa do tweet e legitimá-lo por meio do retweet (republicação do tweet em seus próprios perfis). Cria-se, assim, uma rede de pessoas que buscam construir o significado de determinado acontecimento e que se legitimam mutuamente por meio de mecanismos que a rede social propicia. O significado sobre esse acontecimento pode estar baseado em ideias distorcidas ou tendenciosas sobre o que o "outro lado" realmente pensa e faz, mas isso não impede a rede de ser criada e dos usuários que a integram de se fortalecerem mutuamente. Não é de se surpreender, portanto, que estes ambientes sejam propícios para a criação e propagação de fake news como, por exemplo, a hashtag (palavras-chave ou termos associados a uma informação ou tópico de discussão, que se forem antecedidas pelo símbolo cerquília "\#", funcionam como hiperlinks indexáveis pelos mecanismos de busca da rede) "\#InvestigarJeanWylls", que falsamente tenta atribuir ao então deputado federal Jean Wylls, de esquerda e conhecido pela defesa da 
questão LGBT, uma associação com o caso do atentado a Jair Bolsonaro, ocorrido durante sua campanha eleitoral para à presidência, em 6 de setembro de 2018. Jean Wyllys anunciou, em 24 de janeiro de 2019, que iria desistir de assumir o terceiro mandato como deputado federal pelo estado do Rio de Janeiro, garantido nas eleições de 2018, e que iria deixar de viver no Brasil.

\section{Movimento Brasil Livre}

Se as análises anteriores demonstram a grande maleabilidade que o ciberespaço proporciona para a construção descentralizada de significados, narrativas e discursos; e para a disputa horizontal entre diferentes posições politicas que disputam espaço, escolhemos uma análise do caso do Movimento Brasil Livre (MBL) e das fake news para dar o exemplo de um caso que pode. de certa forma, caminhar no oposto: evidenciar o poder de influência de uma organização vertical, formal, na atividade ciberativista descentralizada na Internet. Também escolhemos esse caso por esse ser, até onde pudemos averiguar através de pesquisa em jornais e sites, o único caso conhecido e verificado na época de uma ligação entre uma organização formal e a prática das fake news, no contexto brasileiro.

Uma análise da atuação do MBL pode nos ajudar a desvendar o funcionamento do continuum entre agências soft" e hard, como elas se cruzam e como se movem dentro da influência dos "materiais não humanos" da Internet. O MBL é uma organização de cunho liberal, situando-se politicamente à direita, que ganhou destaque ao ter protagonismo, desde 2014, em manifestações pelo impeachment de Dilma Rousseff, que ocorreu em 2016. Desde então, se tornou um dos grupos politicos mais conhecidos, também pela sua militância virtual; sua ligação com políticos e partidos situados à direita ou centro-direita como Eduardo Cunha4 4 , Democratas (DEM) 5 , Partido Social Liberal (PSL), Partido da Social Democracia Brasileira (PSDB), Partido da República (PR), Pro- gressistas (PP), entre outros; e pela organização de movimentos contra a ocupação de escolas, a chamada "primavera secundarista", em 2016.

Em 25 de julho de 2018, o Facebook, que sofre pressão no tema das fake news desde que admitiu que sua plataforma havia sido utilizada para influenciar a opinião pública na eleição norte-americana de 2016, por meio de perfis falsose outros métodos para disseminação de notícias e informações falsas, anunciou que havia retirado de sua plataforma uma rede de 196 páginas e 87 perfis brasileiros que violavam suas políticas de autenticidade. Em nota de seu portal de notícias oficial, afirmou que "Essas Páginas e Perfis faziam parte de uma rede coordenada que se ocultava com o uso de contas falsas no Facebook, e escondia das pessoas a natureza e a origem de seu conteúdo com o propósito de gerar divisão e espalhar desinformação" (Gleicher 2018). Inicialmente, a nota do Facebook não informava o nome dessas páginas e perfis (depois de 6 de agosto de 2018, a nota foi atualizada com um link para download de uma lista das 196 páginas removidas). No entanto, segundo fontes do portal de notícias Reuters, a rede era administrada por membros importantes do MBL, e o grupo, em nota divulgada pelo Twitter, confirmava que diversos de seus coordenadores haviam sido afetados (Haynes 2018). Os critérios são explicados pelo próprio Facebook nos seus "Padrões de Comunidade":

Reduzir a disseminação de notícias falsas no
Facebook é uma responsabilidade que levamos
a sério. l... Existe uma linha tênue entre notícias
falsas e sátiras ou opiniões. Por esse motivo,
não removemos noticias falsas do Facebook,
mas, em vez disso, reduzimos significativamen-
te sua distribuição. (Facebook, s.d.)

Dessa forma, fica claro que o Facebook não decidiu retirar as páginas por uma avaliação da veracidade das notícias veiculadas, visto que isso abriria espaço para questionar seus critérios e sua imparcialidade, e sim por detectarem o uso de contas falsas. Ainda nos "Padrões de Comunidade", o Facebook afirma que

\footnotetext{
$4 \quad \mathrm{Na}$ "Marcha para Brasilia", movimento para pressionar congressistas pelo impeachment de Dilma.

5 Fernando Holiday, Kim Kataguiri e Arthur Moledo do Val, alguns dos coordenadores e membros do MBL, foram eleitos como, respectivamente, vereador, deputado federal e deputado estadual por esse partido, na cidade de São Paulo.
} 
os usuários não devem se envolver em 'comportamento não autêntico', que inclui criar ou gerenciar 'contas falsas; contas com nomes falsos; contas que participam de comportamentos não autênticos coordenados, ou seja, em que múltiplas contas trabalham em conjunto' com a finalidade de 'enganar as pessoas'. (Melo 2018)

A acusação, então, não é feita por uma análise direta do conteúdo, mas pela detecção de comportamento irregular nas páginas e perfis, o que serve de contra-argumento às acusações de "censura" por parte do MBL, que pediu provas para a exclusão das páginas. O site Reuters diz, ainda, que

as páginas desativadas, que juntas tinham mais de meio milhão de seguidores, variavam de notícias sensacionalistas a temas políticos, com uma abordagem claramente conservadora, com nomes como Jornalivre e O Diário Nacional. Ao deturpar o controle compartilhado das páginas, os membros do MBL eram capazes de divulgar suas mensagens coordenadas como se as notícias viessem de diferentes veículos de comunicação independentes, de acordo com as fontes. (Haynes 2018)

O MBLjá havia utilizado notícias falsas: foi condenado pelo Tribunal Regional Eleitoral (TRE) da Bahia a publicar nota de resposta do candidato ao Senado Jacques Wagner, do Partido dos Trabalhadores (PT), em suas redes sociais, depois de publicar um vídeo de protesto contra petistas (que, na ocasião, participavam de ato a favor do ex-presidente Luiz Inácio Lula da Silva), no qual afirmavam falsamente, com uma legenda no vídeo, que os manifestantes protestavam contra Jacques Wagner ("Jacques Wagner e petistas são vaiados dentro de shopping"), quando na verdade o mesmo não estava presente no local (Pitombo 2018).

Decerto, não é papel deste artigo determinar se o MBL ou o Facebook estão "certos" ou não nesta discussão, e sim analisar a prática ciberativista do MBL. O MBL pode ser entendido como situado no polo hard do continuum de definições de agência que podemos utilizar para entender a variedade de ações políticas que ocorrem no ciberespaço. É uma organização política, caracterizada pela ação política profissional, que mobiliza militantes e/ou simpatizantes fortemente engajados em projetos políticos estruturados, e estabelece um roteiro conscientizado de ações, com definição de meios, metas e monitoramentos. Já as "curtidas" e compartilhamentos de fake news, ou mesmo de notícias que não se encaixem exatamente nesse conceito mas sejam simplistas, tendenciosas ou não propriamente verificadas, em uma rede social como o Facebook podem ser inseridas no polo soft desse continuum: são agenciamentos políticos, mas são fragilmente conscientizados, motivados por impulsos momentâneos, sem necessidade de grandes esforços reflexivos. O ciberespaço e, especificamente, a plataforma do Facebook, permitem que esses agenciamentos políticos frágeis ganhem um peso e relevância inimagináveis no mundo off-line. No Facebook, esses impulsos momentâneos podem ser instrumentalizados para a grande circulação de ideias, posicionamentos, figuras políticas que determinados grupos tenham interesse em divulgar. Os usuários da plataforma podem dar seu apoio a causas, movimentos, posições políticas com uma simples "curtida" ou compartilhamento, e é uma ação que se faz de forma tão fácil, está tão ao alcance de todos, não exigindo nenhum grande comprometimento, que pode-se dizer que é uma ação incentivada pelo funcionamento da plataforma.

Além do fato de que a agência política com baixa intencionalidade conscientizada ganha uma nova relevância no mundo on-line por causa da otimização maquínica, que permite que essa agência ganhe volume (pela soma de vários gestos desse tipo de agenciamento político juntos) e cause efeitos no mundo político, e de que a agência política conscientizada na Internet, por parte da ação livre dos indivíduos, muitas vezes supera até mesmo a ação coletiva das organizações formais (partidos, ongs, grupos de pressão etc.), podemos identificar um fenômeno específico, baseado nessa análise do MBL: a união, ou coordenação, entre o polo hard e o polo soft da agência política, possivel apenas pela configuração específica das plataformas disponiveis a esses atores no ciberespaço.

É possivel que o MBL, ao buscar a criação de uma rede para a circulação em massa do seu conteúdo - composto por posicionamentos 
sinceros ou fake news ${ }^{6}$ - estivesse planejando uma estratégia que conscientemente se utiliza do polo soft e dos instrumentos das plataformas que mobilizam esse polo. O MBL tem um projeto político, coordena suas ações com definição de meios, metas e monitoramento, logo, a criação de uma rede de notícias falsas ou tendenciosas seria pensada especificamente de acordo com o funcionamento do ciberespaço, na qual se sabe que os usuários de determinada plataforma vão divulgar os conteúdos de forma massiva. Seria necessária uma pesquisa mais volumosa para realmente confirmar a existência dessa estratégia por parte dessa organização, mas propomos a possibilidade como exercício, para refletirmos sobre os caminhos pelos quais organizações formais e verticais podem buscar direcionar a ação descentralizada da Internet. O polo soft da agência política seria conscientemente reconhecido e instrumentalizado pelo polo hard, mas o primeiro não saberia disso: os individuos que exercem agência política situada no polo soft no ciberespaço não sabem que suas ações virtuais de baixa intencionalidade beneficiam esse ou aquele grupo político, podem nem mesmo cogitar essa possibilidade, podem nem mesmo perceber qualquer valor, relevância ou legitimidade na ação política virtual, podem acreditar até mesmo que suas ações são em grande parte "apolíticas", baseadas em uma preocupação essencialmente "neutra" em relação a temas preocupantes, uma preocupação essencialmente individual, distante de qualquer aspecto da política tradicional, tida como o espaço da corrupção, da busca egoísta pelo interesse próprio, por cargos no Estado. De modo que as preocupações individuais não são nem mesmo vistas como preocupações "politicas", porque a "política" pode ser majoritariamente vista como tendo a ver com cargos e com o Estado, algo distante. Não há, no geral, cálculo político organizado e de longo prazo por parte dos agentes do polo soft. Segundo a Nota Técnica \#2, "A difusão dos boatos sobre Marielle Franco: do Whatsapp aos sites de notícias", do Monitor do Debate Público no Meio Digital, grupo de pesquisa dos professores da Escola de Artes, Ciências e Humanidades (EACH) Pablo Ortellado e Márcio Moretto, que pesquisou, entre os dias 26 de março e 3 de abril de 2018, por meio de questionário, com respostas de 2.520 pessoas, sobre informações falsas referentes à vereadora Marielle Franco, divulgadas pelo WhatsApp, "os boatos circularam mais por grupos de familiares (51\%) do que por grupos de amigos (32\%) ou de colegas de trabalho (9\%)" (Ortellado, Ribeiro, 2018, 1) elemento que demonstra a baixa intencionalidade da atividade ciberativista de compartilhar um boato de WhatsApp, visto que espaços como grupos de familiares costumam ser vistos como ambientes descontraidos, despreocupados, intimos, onde receberemos menos julgamento pelo que comentamos ou compartilhamos. É uma atividade ciberativista, pois se trata de um ato político (a concordância ou discordância com determinada informação a ponto de compartilhá-la pode ser considerada política, mesmo determinados vieses de confirmação podem ser considerados influenciados pela política), mas é um ato político "econômico", de agência fragilmente conscientizada (situada no polo soft), sem grande planejamento sobre seus desdobramentos ou mesmo reflexão sobre ser de fato um ato político.

Nas eleições de outubro de 2018, alguns portais de notícia denunciaram que empresas estariam comprando pacotes de disparos em massa de mensagens contra o PT no Whatsapp. A prática é ilegal por se tratar de doação de campanha não declarada e por empresas. Um dos acusados pelas fontes da matéria da Folha de S. Paulo foi Jair Bolsonaro, à época candidato à eleição (Mello 2018). A matéria acusa práticas ilegais por parte de empresas de impulsionamento de conteúdos como disparos de mensagens em massa usando base de dados de terceiros (fornecidas ilegalmente por empresas de cobrança ou por funcionários de empresas telefônicas), segmentação por região geográfica,

\footnotetext{
6 É notório que as fake news são tidas como extremamente benéficas de se divulgar para um grupo político, afinal, tendem a espalhar informações absurdas pensadas especificamente para distorcer situações políticas, difamar adversários, fomentando um nivel enorme de revolta em relação a essas posições e figuras adversárias e, consequentemente, criando adesão ao posicionamento do grupo que se beneficia.
} 
renda, e entre membros de grupos de Whatsapp "apoiadores, detratores e neutros" (Mello 2018).

A discussão se tornou polêmica porque se fossem constatadas práticas ilegais e abuso de poder econômico, uma chapa concorrente à eleição poderia ser cassada. De qualquer forma, comprovado ou não, se trataria de mais um exemplo de organizações políticas formais, tradicionais, políticos profissionais etc., pertencentes ao polo hard do continuum de agência política, se utilizando das ações de baixa intencionalidade do polo soft para a divulgação em massa de conteúdos que beneficiem figuras e grupos politicos especíicos. As notícias falsas espalhadas em massa no Whatsapp chegaram até mesmo a ser mencionadas e utilizadas como argumento por candidatos nas entrevistas e debates eleitorais televisionados nas eleições de 2018: Jair Bolsonaro, em atitude que já havia tido em outras ocasiões, em entrevista televisionada afirmou que o livro Aparelho Sexual e Cia, livro francês de educação sexual, escrito por Hélène Bruller, teria sido distribuido nas escolas brasileiras pelo Ministério da Educação (MEC) e seria parte do "Kit Gay" (apelido pejorativo para o programa "Brasil Sem Homofobia") do PT e do então candidato Fernando Haddad, uma acusação que teve que ser desmentida pelo Tribunal Superior Eleitoral, pois o livro não foi distribuido pelo MEC e nem fazia parte do programa "Brasil Sem Homofobia", que na verdade nem mesmo chegou a ser executado (Ramalho 2018).

Seis em cada dez brasileiros têm o aplicativo de mensagens Whatsapp no celular. O grupo de checagem de fatos Aos Fatos reuniu, em uma matéria do El País, as cinco informações falsas mais divulgadas em redes sociais, principalmente pelo Whatsapp: "O "kit gay" para crianças de 6 anos que foi distribuido nas escolas", "O homem que apunhalou Bolsonaro é filiado ao PT e aparece numa foto com Lula", "A senhora agredida por ser eleitora de Bolsonaro (que na verdade era Beatriz Segall).", "Haddad defende o incesto e o comunismo em um de seus livros", e "Se Haddad chegar ao poder, pretende legalizar a pedofilia" (Barragán 2018). Além do fato de que muitas dessas fake news são divulgadas apenas com imagens, montagens etc., as empresas disponibilizam planos com dados ilimitados, mas apenas para aplicativos como Whatsapp e Facebook. Isso significa que, mesmo que uma pessoa receba uma fake news com um link, se o pacote de dados tiver acabado, ela só vai poder utilizar o Whatsapp e, caso tente abrir o link para ler a notícia e checar a veracidade, ela não vai ter acesso (Gragnani 2018). A única fonte de informação será o próprio Whatsapp.

\section{Conclusão}

É possivel estabelecer padrões em diferentes tópicos de discussão, sobre diferentes assuntos. Como, por exemplo, os mesmos memes sendo utilizados repetidamente, os mesmos "chavões" de posições políticas de esquerda ou direita, e as mesmas análises de conjuntura sobre questões mais gerais da política nascendo desses diferentes tópicos. Com esses padrões estabelecidos, é possivel tipificar e analisar as motivações e a intencionalidade das manifestações, dependendo de sua originalidade e do tempo e esforço gastos que podem ser notados nelas.

No exemplo do grupo "Vizinhos do Centro Histórico - POA", percebemos que o acontecimento de uma reintegração de posse em uma ocupação, ao ser divulgado em um grupo virtual com 30 mil usuários, permite um engajamento em tempo real que não seria possivel sem a Internet. A forma "tradicional" de convocar pessoas para o engajamento de tempo real em um acontecimento como esse é a convocação por parte de organizações políticas tradicionais, como partidos; neste caso, apenas os militantes e simpatizantes teriam acesso à informação e estariam presentes no dia e hora em que ocorresse. Em um grupo virtual, a informação pode ser propagada em tempo real para um enorme número de pessoas. Surgem, então, inúmeras possibilidades de ativismo: tanto pessoas que se envolvem em militância política fora da internet que queiram divulgar o acontecimento, quanto pessoas que não podem, ou não se sentem suficientemente inclinadas a responder ao chamado presencial, mas querem 
se manifestar de alguma forma. O grupo permite esse engajamento ciberativista com grau menor de intencionalidade e monitoramento a longo prazo dos efeitos, tanto na pessoa que se posiciona, quanto a que apenas curte um comentário, compartilha uma postagem ou faz um meme.

O ciberespaço se caracteriza pela presença de habitantes que estão buscando uma quebra do ordinário, um ambiente propício para a proliferação em rede de desdobramentos a partir de um acontecimento político. A reintegração de posse da ocupação Lanceiros Negros, ao ser publicada no grupo "Vizinhos do Centro Histórico" pode ser entendida, portanto, como um "ciberacontecimento" que impulsiona o ciberativismo, um acontecimento que, ao se tornar virtual, "desencadeia uma rede de agenciamentos que tensionam os sistemas estruturados de percepção social acerca de algum tema político ou politizável" (Jungblut 2015, 18), cria uma explosão de disputas de narrativas e interpretações entre os frequentadores do ciberespaço, de modo que podemos dizer que, por meio dessas disputas e dessas redes de desdobramentos, impulsionada pelos agentes humanos e não humanos (as diversas plataformas, os vídeos, as fotos, os memes, os emoticons etc.), ocorre uma construção social do significado desse ciberacontecimento.

O exemplo do "Movimento Brasil Livre" demonstra como podemos identificar, por meio da análise do funcionamento da influência dos materiais não humanos, o relacionamento entre o que determinamos como agenciamentos do polo "soft" e do polo "hard" do continuum de definições de agência. As possibilidades abertas pelo modo como nos influenciam os materiais não humanos podem ser positivas, permitindo um ativismo politico livre das amarras tradicionais e institucionais, burlando o bloqueio das mídias e organizações tradicionais e permitindo a ação ativista para mais pessoas e de forma a visibilizar causas que não seriam tão perceptiveis de outra forma. Por outro lado, é possivel que as organizações tradicionais tomem consciência da ação dos materiais não humanos e da possibilidade de ativismo de baixa intencionalidade que esses abrem, de modo a se utilizar dessa possibilidade de ativismo para turbinar os seus objetivos políticos de alta intencionalidade e alto planejamento em relação aos seus desdobramentos. Dessa forma, toda uma rede de ação ciberativista descentralizada pode ser de certa forma centralizada de acordo com um planejamento. Não se trata necessariamente, no entanto, de um determinismo; portanto, cabe investigar as possiveis "quebras de protocolo" que a ação ciberativista pode causar, os efeitos não planejados que podem ocorrer pela influência de atores ciberativistas específicos ou dos atores não humanos.

\section{Referências}

Ahearn, Laura. 2001. "Language and Agency". Annual Review of Anthropology, n. 30: 109-137. https://doi. org/10.1146/annurev.anthro.30.1.109

Araújo, Willian Fenandes. 2011. "Ciberativismo: levantamento do estado da arte na pesquisa no Brasil". in Anais do V Simpósio Nacional Da Associação Brasileira De Pesquisadores Em Cibercultura (ABCiber), Florianópolis, SC, Novembro 16 a 18, 1-15. Florianópolis, SC, UFSC.

Barragán, Almudena. 2018. "Cinco 'fake news' que beneficiaram a candidatura de Bolsonaro". El Pais, Outubro, 19, 2018. Acesso julho 15, 2019. Disponivel em: https://brasil.elpais.com/brasil/2018/10/18/actualidad/1539847547_146583.html

Barros, C. J. 2019. "Com medo de ameaças, Jean Wyllys, do PSOL, desiste de mandato e deixa o Brasil". Folha de São Paulo, Janeiro, 24, 2019. Acesso Fevereiro 05, 2020. Disponivel em: https://www1.folha.uol.com. $\mathrm{br} / \mathrm{poder} / 2019 / 01 / \mathrm{com}-\mathrm{medo}-\mathrm{de}-a m e a c a s-j e a n-$ - wyllys-do-psol-desiste-de-mandato-e-deixa-o-brasil. shtml?utm_source=twitter\&utm_medium=social\&utm _ campaign=twfolha

Bennett, Lance and Alexandra Segerberg. 2012. "The logic of connective Action". Information, Communication \& Society 15(5): 739-768. https://doi.or$\mathrm{g} / 10.1080 / 1369118 \times .2012 .670661$

Braga, Renê Morais da Costa. 2018. "A indústria das fake news e o discurso de ódio". in Direitos politicos, liberdade de expressão e discurso, Viana Rodolfo Viana Pereira, org, volume I, 203-220. Belo Horizonte: Instituto para o Desenvolvimento Democrático.

Cardoso, Isabella dos Santos. 2016. "O riso cruel nas mídias sociais: um estudo dos memes do impeachment de Dilma Rousseff". Monografia em Jornalismo. UFRJ/ ECO, Rio de Janeiro.

Gleicher, Nathaniel. 2018. "Garantindo um ambiente autêntico e seguro". Facebook, Julho, 25, 2018. Acesso Julho 15, 2019. Disponivel em: https://br.newsroom. fb.com/news/2018/07/garantindo-um-ambiente-autentico-e-seguro 
Gragnani, Juliana. 2018. "Como planos de celular com Facebook e WhatsApp ilimitados podem potencializar propagação de notícias falsas". UOL, Abril 16, 2018. Acesso Julho 15, 2019. Disponivel em: https://noticias. uol.com.br/tecnologia/noticias/bbc/2018/04/16/ como-planos-de-celular-com-facebook-e-whatsapp-ilimitados-podem-potencializar-propagacao-de-noticias-falsas.html.

Haynes, Brad. 2018. "Facebook retira do ar rede ligada ao MBL antes das eleições". Reuters, Julho 25, 2018. Acesso Julho 15, 2019. Disponivel em: https:// br.reuters.com/article/domesticNew//idBRKBN1KF1MI-OBRDN?fbclid=IwAR3UvrVm3yoiXdCLgDS5T5dTaTzmc_gledcEocPcJnwtahgm7uTB3dX288Y

Jungblut, Airton L. 2011. "Ciberacontecimentos: reflexões etnográficas sobre o extraordinário no mundo on-line". Civitas - Revista de Ciências Sociais, v. 11: 361-372. https://doi.org/10.15448/1984-7289.2011.2.9651

Jungblut, Airton L. 2015. "Práticas ciberativistas, agência social e ciberacontecimentos". Vivência - Revista de Antropologia: 18-21.

Klang, M. and N. Madison. 2016. "The domestication of online activism". First Monday 21, n. 6: 1-3, June 6, 2016. Acesso June 29, 2019. https://journals.uic.edu/ ojs/index.php/fm/article/view/6790

Latour, Bruno. 2008. Reensemblar lo social: una introducción a la teoria del actor-red. Buenos Aires: Manantial.

Lemos, André. 2004. "Ciberativismo". Acesso Fevereiro 04, 2020. http://Www.facom.ufba.br/ciberpesquisa/ lemos/ciberativismo.pdf.

Mello, P. C. 2018. "Empresários bancam campanha contra o PT pelo WhatsApp". Folha de São Paulo, Outubro 18, 2018. Acesso Julho 15, 2019. https://www1.folha.uol. com.br/poder/2018/10/empresarios-bancam-campanha-contra-o-pt-pelo-whatsapp.shtml.

Melo, Débora. 2018. "Caso MBL: Facebook não remove fake news, e sim contas falsas". HuffpostBrasil, Julho 27, 2018. Acesso Junho 29, 2020. https://Www. huffpostbrasil.com/2018/07/27/facebook-nao-remove-fake-news-mas-exclui-contas-falsas-entenda-a-acao-contra-o-mbl_a_23491062/

Ortellado, Pablo e Márcio Moretto Ribeiro. 2018. "Nota Técnica \#2. A difusão dos boatos sobre Marielle Franco: do WhatsApp aos sites de notícias". Monitor do debate político no meio digital, 2018. Monitor Digital, Abril 20, 2018. Acesso Maio 03, 2018. https://wwww.monitordigital. org/2018/04/20/nota-tecnica-02/

Ortner, Sherry. 2007. "Poder e Projetos: reflexões sobre a agência". in Conferências e diálogos. Saberes e práticas Antropológicas, organizado por M. Grossi; C. Eckert; P. Fry, 45-80. Brasilia: ABA; Blumenau: Nova Letra.

Padrões da Comunidade, Facebook. s.a. 2020. 21. Notícias Falsas. Acesso Junho 29, 2020. https://WwW. facebook.com/communitystandards/false_news

Pereira, M. B. 2018. "\#EleiçãoSemLulaÉFraude x \#MoluscoNaCadeia: Memes no julgamento do Lula e o confronto de enquadramentos por meio do humor." Monografia, Instituto de Ciência Política (IPOL), Universidade de Brasília (UnB).
Pitombo, J. P. 2018. "MBL é condenado por TRE por publicar notícia falsa sobre Jaques Wagner (PT)". Folha de São Paulo, Agosto 24, 2018. Acesso Julho 15. 2019. https://Www1.folha.uol.com.br/poder/2018/08/ mbl-condenado-por-tre-por-publicar-noticia-falsa-sobre-jaques-wagner-pt.shtml.

Ramalho, Renan. 2018. "TSE manda remover da internet vídeos de Bolsonaro com críticas a material contra homofobia". G1, Outubro 16, 2018. Acesso Julho 15, 2019. Disponivel em: https://g1.globo.com/politica/eleicoes/2018/noticia/2018/10/16/tse-manda-remover-da-internet-videos-de-bolsonaro-contra-o-kit-gay.ghtml

Rodrigues LR e FJP Pimenta. 2015. "Discussões sobre o conceito de ciberativismo e suas práticas atuais através de uma abordagem pragmaticista". Anais do XXXVIII Congresso Brasileiro de Ciências da Comunicação, Rio de Janeiro, RJ, Setembro 4 a 7, 2015, 1-12. Rio de Janeiro, Intercom - Sociedade Brasileira de Estudos Interdisciplinares da Comunicação.

Sewell, William H., Jr. 1992. "A theory of structure: duality, agency, and transformation". American Journal of Sociology, 98(1): 1-29. https://doi.org/10.1086/229967

Silveira, Sergio Amadeu. 2009. "Redes cibernéticas e tecnologias do anonimato". Comunicação \& Sociedade, Ano 30, n. 51, jan./jun: 113-134. https://doi. org/10.15603/2175-7755/cs.v30n51p113-134

Uhr, Felipe. 2016. "Lanceiros Negros: presente em construção, futuro incerto". Já, Julho 16, 2016. Acesso Fevereiro 15, 2020. http://www.jornalja.com.br/lanceiros-negros-presente-em-construcao-futuro-incerto/

\section{Ana Nolasco}

Estudante de Ciências Sociais pela Pontificia Universidade Católica do Rio Grande do Sul (PUCRS), em Porto Alegre, RS, Brasil.

\section{Leonardo Frosi Ávila}

Estudante de Ciências Sociais pela Pontificia Universidade Católica do Rio Grande do Sul (PUCRS), em Porto Alegre, RS, Brasil.

\section{Airton Luiz Jungblut}

Doutor em Antropologia Social pela Universidade Federal do Rio Grande do Sul (Ufrgs), em Porto Alegre, RS, Brasil. Professor da graduação e do PPG em Ciências Sociais da Pontificia Universidade Católica do Rio Grande do Sul (PUCRS), em Porto Alegre, RS, Brasil. 